\section{AUTHORS}

Michael T. Brandt ${ }^{\mathrm{a}, \mathrm{b}}$

Steven P. Levine ${ }^{\mathrm{b}}$

Dean G. Smith ${ }^{c}$

Harry J. Ettinger

${ }^{a}$ Los Alamos National Laboratory, Environmental, Safety and Health Division,

Los Alamos, NM 87545;

${ }^{b}$ Erb Environmental

Management Institute and

World Health Organization

Collaborating Center, School of

Public Health, University of

Michigan, Ann Arbor, MI

48109-2029;

cDepartment of Health

Management and Policy,

University of Michigan School of

Public Health, Ann Arbor, MI 48109-2029.

\title{
Activity-Based Cost Management Part I: Applied to Occupational and Environmental Health Organizations
}

The fundamental purpose of an environmental, safety, and health (ES\&H) department or program-to assure worker health and safety and prevent environmental degradation-can be preserved by managers who can use contemporary business management tools to solve complex business and budgetary problems. Traditional cost accounting methods do not provide ES\&H managers with the cost data and business process information required to make informed and timely decisions. Activity-based cost management (ABCM) is a business tool that can be used to quantify the cost of ES\&H work activities and the cost of developing and delivering ES\&H products and services. Additionally, the cost data and business process information that result from applying $A B C M$ can be used to understand why these costs exist. The concepts, principles, and nomenclature associated with the two components of ABCMactivity-based costing ( $A B C)$ and activity-based management ( $A B M)$-are discussed in this article, as is the utility of ABCM as a tool for managing ES\&H departments and programs. Keywords: activity-based cost management, activity-based costing, activity-based management, management, case study, environmental and occupational health

$\mathrm{B}$ eginning in 1995 the Occupational Health and Safety Policy Group at The University of Michigan began investigating the application of different business, management, accounting, economic, and policy tools to occupational and environmental health organizations. One tool, activity-based cost management $(\mathrm{ABCM})$, was the subject of a doctoral dissertation that explored the application of $\mathrm{ABCM}$ in three case studies of environmental, safety, and health (ES\&H) organizations. ABCM is discussed in this article in three sections. In the first section, the impacts associated with the economic pressures facing all ES\&H organizations, both private and government, are discussed. The limitations of conventional cost accounting in managerial decision making is briefly introduced as part of a discussion about the evolution of ABCM as a cost accounting tool method. The next section introduces the key concepts, principles, and nomenclature of this new cost accounting method. Finally, the usefulness of
$\mathrm{ABCM}$ as a management tool is discussed using the findings of the case study research.

\section{ECONOMIC PRESSURES}

$D$ uring the 1990s the workplace has grown more complex and business competition has increased worldwide. More advanced information technology, greater product diversity, shorter product life cycles, increased quality requirements, more regulatory oversight, and greater competition have motivated organizations to focus on ways to respond to market changes and deliver products cheaper, better, and faster. ${ }^{(1,2)}$ All organizations, whether nonprofit or for profit, are experiencing these competitive pressures. They are searching for ways to reduce costs through downsizing, reengineering business processes, implementing quality management, outsourcing, and changing cost management practices. Support departments that provide services internal to a company or government agency 
such as human resources, legal, and ES\&H are often the first departments targeted for cost reduction and cost control initiatives because these functions are part of a rapidly increasing overhead cost. ${ }^{(3)}$ These departments are typically viewed as growing costs and as functions that do not contribute financially to the revenue and income side of an organization.

Through a recent survey, ES\&H professionals expressed concern about an increased probability of future budget cuts in their organizations, greater difficulty selling major investments in ES\&H to senior managers, and an increased need to quantify and justify the value and contribution of their function to their organizations. ${ }^{(4)}$ Their departments and programs must compete with other overhead functions for an ever-shrinking pool of funding. In response to these business pressures, some organizations have decided to outsource ES\&H departments, reduce the number of ES\&H professionals on staff through layoffs, introduce cost-cutting measures, close consulting offices, and consolidate ES\&H operations. ${ }^{(5-8)}$ To compete in such an aggressive economic environment, managers need to understand the factors affecting the behavior and causes of costs so they can be managed.

\section{Typical Response to High Costs}

Typically, when costs are considered too high they are cut uniformly across organizations. Spending may be controlled by imposing a fixed percentage reduction in each support department. Other cost control tactics commonly focus on reducing the cost of labor through early retirement incentives, layoffs, outsourcing support departments, and by freezing salary increases and new hiring. Such budget reduction and cost saving tactics are made in the absence of information about the demand for the products and services produced by the overhead departments. Traditional cost accounting systems are not capable of providing information to identify the causes and location of excessive costs. Accounting researchers Kaplan and Thomas have found that traditional accounting practices and systems provide "managerial accounting information that is too late, too aggregate, and too distorted to be relevant for managers' planning and control decisions." ${ }^{(9)}$ The net result of decision making without cost data and business process information is a downward spiral in which overhead organizations are increasingly unable to respond to the demand of their internal customers, and the quality and responsiveness of the service provided often deteriorates.

\section{Traditional Cost Accounting and Activity Transactions}

Traditional cost accounting systems were designed for use in factories where overhead costs were low, there were few product lines, and manufacturing was labor intensive. As a result, there was little incentive to spend the time and money to develop a finely tuned accounting system to track, manage, and control overhead costs. $^{(10)}$ But because overhead costs have grown as product line diversity and complexity has increased, manufacturing firms began examining the causes of these costs. Miller and Vollmann have suggested that managers examine the causes of overhead and indirect costs, which have increasingly become logistical transactions (scheduling material movements, production runs, and customer shipments) and information exchange transactions (product and process-related, and service-related such as ES\&H). ${ }^{(11)}$ In manufacturing, a change in a product creates an initial transaction that causes a cascade of additional transactions between departments, where one department serves as a supplier of a product or service to another department.

ES\&H managers, like production managers, have an oppor- tunity to control and manage the costs they create by controlling and managing the transactions that drive them. For example, substituting a less toxic raw material in a manufacturing process for a carcinogenic raw material is an initiating transaction that will likely result in changes in health protection activities such as work practices and personnel protective equipment. The actions taken by the industrial hygiene and production departments in response to this change are transactions that incur cost to the organization. In this case an industrial hygienist will supply regulatory, work practice, and other health protection guidance, which are information exchange transactions. The production department, which is the recipient of the guidance, is the customer and a participant in the transaction. These managers can focus on activities that will optimize the production of manufactured products while protecting the health and safety of workers. Simultaneously, these managers can also optimize the production, delivery, and use of ES\&H products and services by the production department. These outcomes can be achieved only if the managers know the causes of costs and which activities exhibit the highest costs.

\section{Alternative Response to High Costs}

ES\&H managers who are experiencing economic pressure cannot afford to make uninformed decisions about reducing costs. The business, management, and economics literature discusses the consequences of using misleading information provided by traditional cost accounting systems to make the wrong decisions. ${ }^{(12-14)}$ To avoid comparable negative outcomes in service organizations, ES\&H managers need timely and accurate cost performance feedback on the efficiency and effectiveness of operations to compete for increasingly limited overhead funding. They must, however, also know which work activities are critical for maintaining the technical integrity of their ES\&H programs. Combining the technical knowledge of ES\&H programs with the business knowledge that work activities create transactions, which generate costs, is important in understanding how activities can be managed to control their costs.

$\mathrm{ABCM}$ is a cost management system in which costs are assigned to the product or service that caused the transaction. ABCM can be used to quantify the cost of ES\&H work activities. Managers can use ABCM to identify the causes of cost by examining activities linked together as a business process that create products and services of value to customers. By combining activity cost data with a deeper understanding of the causes of cost and the logical relationships among activities, managers can develop ways to streamline and optimize the execution of high-cost activity transactions to control costs.

$\mathrm{ABCM}$ can also be used to quantify more accurately the cost of products and services produced than can traditional cost accounting methods. ${ }^{(14,15)}$ Accordingly, the distortion of product and service costs is avoided by using ABCM to trace activity costs to products or services based on their demand and use of specific work activities and their resources. For example, if a product is manufactured with a raw material of low toxicity instead of a carcinogenic raw material, the demand by that product for health protection products and services will be lower. The costs associated with those health protection activities will only flow to the product or service that demanded and used them.

ABCM has been applied and successfully implemented by service organizations. ${ }^{(16-18)}$ Each of these newly developed transaction-based costing systems examined activities performed in the organization as the first step in learning about and understanding cost behavior. As a result, the focus of cost accounting shifted (1) 


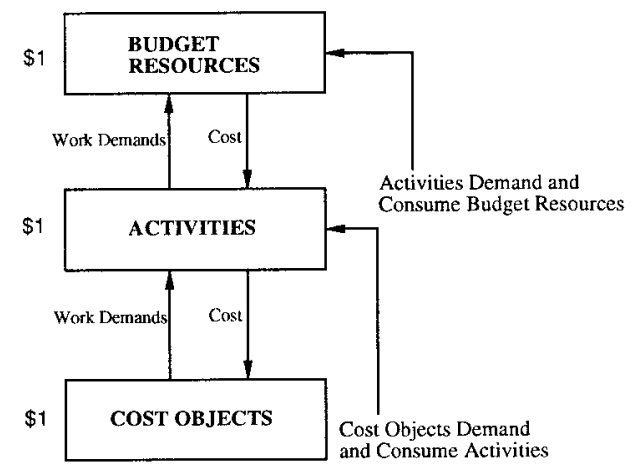

- ABC Decomposes Costs

- Traces Costs from Budget Resources to Activities to Cost Objects

- Work Demands Originate with Cost Objects and Flow in Reverse of Costs Through Activities to Budget Resources

- Costs Flow Toward Cost Objects

- Resource Costs $=$ Activity Costs $=$ Cost Object Costs

FIGURE 1. Principles of $A B C M$

from allocating costs to tracing costs through activities to products, services, and customers; and (2) from determining the cost of supplying budget resources (labor, materials, etc.) to determining the cost of using resources to create products. ${ }^{(10)}$

\section{ABCM}

$\mathbf{A}^{\mathrm{B}}$ BCM is applied and used to build cost models for an organization using the following principles. ${ }^{(19,20)}$

- Products and services (cost objects) demand and consume activities, and activities demand and consume budget resources (see Figure 1).
- Work demands originate with cost objects and flow in reverse of costs through activities to budget resources (see Figure 1).

- Budget resources are traced (not allocated) into activities, and activity costs are traced into cost objects using drivers (see Figure 1). The tracings are based on demand and use. If an activity does not use a resource, resource costs are not traced to the activity. Similarly, if a cost object does not use an activity, activity costs are not traced to the cost object.

- Budget resources are the starting point for cost tracings. Accordingly, the amount of funding found in the budget must equal the amount of money traced into activities, which must equal the amount of money traced into cost objects (see Figure 1).

- Costs are controlled by managing activities, not the inverse.

ABCM consists of two components: activity-based costing $(A B C)$ and activity-based management $(A B M)$. The $A B C$ component of $A B C M$ is a method of measuring the cost of work activities and measuring the cost of products and services produced by those activities. In contrast, the ABM component of $A B C M$ is characterized by how business process information is linked with $\mathrm{ABC}$ cost data and used by managers for making informed and fact-based decisions. Managers can use the data and information generated by ABCM to determine what causes work activities to occur, and how and why resources are used as a way to understand why costs occur. ${ }^{(19)}$

\section{ABC: The Cost Decomposition View}

The cost decomposition view of $\mathrm{ABCM}$ is a cost reassignment method that measures the cost of a product or service based on the actual use of budget resources by work activities, and based on the amount of activities used to produce a product or deliver a service (see Principles 1-4 above). ${ }^{(19,20)}$ Budget resources are the factors of production that are used to perform an activity. They are considered the cost of performing an activity. Activity costs are determined by tracing costs from the budget resources to each activity by using resource cost drivers that reflect the amount of resources consumed by each activity (see Figure 2 ). ${ }^{(19,20)}$ In this way the elements of cost (labor, space, materials, equipment) are assigned to activities based on what is needed to perform the activity.

Activities are usually collected in an activity center, which is a

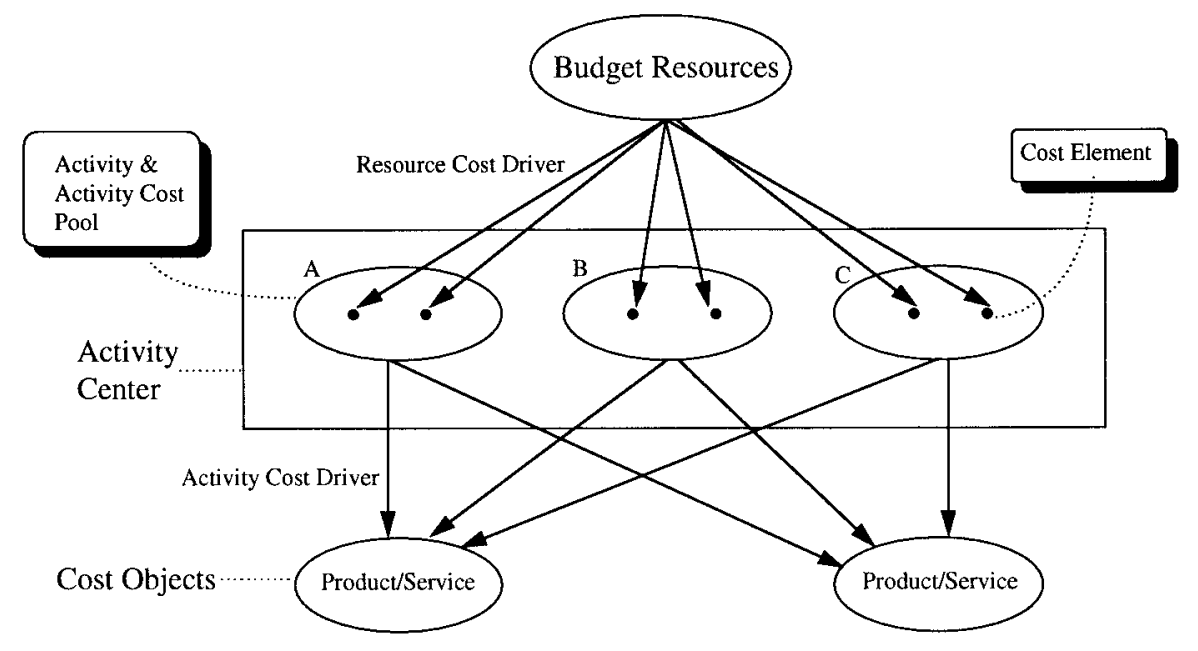

FIGURE 2. Conceptual view of an activity-based costing model 
cluster of activities grouped by a common function or process. There is generally more than one activity found in an activity center as shown by letters $\mathrm{A}-\mathrm{C}$ in Figure 2. For example, a respiratory protection program would be considered an activity center comprised of the following activities: scheduling employees, training and fitting employees with respirators, and issuing respirators to qualified users.

Resources can be traced to an activity by directly charging each activity for the amount of each type of resource used. Alternatively, if data is not available to directly link resources to activities, then the amount of budget resources consumed by each activity can be estimated by interviewing knowledgeable managers, supervisors, and employees about where and how much of each budget resource is used to perform each activity. Direct charging or estimating costs are considered resource cost drivers. Each type of budget resource that is traced into an activity becomes an element of the cost of that activity. The sum of each cost element becomes the total cost of an activity cost pool.

In the second step, activity cost pools are quantitatively linked to products and services by using activity cost drivers. Activity cost drivers assign budget resource costs from activities to cost objects. These drivers reflect the unique consumption patterns of a product or service for specific activities and they measure the use of an activity and its budget resources by the cost object. ${ }^{(19)}$ The cost object is the final point to which all costs are traced. Cost objects are the reason why work activity transactions occur. Without cost objects there is no reason to perform the work. For example, two cost objects associated with a respirator protection program are a trained and fitted employee and an issued respirator. Finally, the activity cost drivers draw a manager's attention to the causes of work.

The ABC view yields quantitative data about what things cost. ${ }^{(19)}$ Using this view the following types of questions can be asked about an ES\&H department or program.

- What resources are required by these activities?

- What are the costs of each ES\&H work activity?

- What are the drivers (causes) of cost in activities, products, and services?

- What are the total and unit costs of activities, products, and services?

- What opportunities exist for improving and optimizing activities, reducing their frequency, or changing/eliminating them to reduce cost?

- What opportunities exist for changing practices to improve ES\&H outcomes?

\section{ABM: The Process View}

The process view, which is ABM, is concerned with the relationship between individual activities logically linked together as a business process. ${ }^{(19,20)}$ Business processes are evaluated in terms of the logical flow of the work activities required to produce products and deliver services, and the relationships among the activities. Work activities represent individual transactions in which the output of one activity becomes the input to drive a subsequent activity in the process. Mapping the relationship among activities and examining these relationships as a business process reveals why and how things cost what they do. ${ }^{(19)}$

$\mathrm{ABM}$ involves analyzing, evaluating, and integrating the cost data generated by the ABCM model with the business process information collected as part of building an ABCM model. The objective of $A B M$ is to move a manager away from the functional and organizational thinking represented by an organizational chart. Instead, the goal is to have a manager begin to think of the work his or her department performs in terms of the amount of budget resources consumed by key activities linked in a business process. For example, Figure 3 illustrates how an organizational chart can be translated into key activities and identifies the level of effort performed by the labor resources traced to each activity. ${ }^{(19)}$ The chart of activities and labor resource assignments is then incorporated into a map of the business process. The business process map will provide information about the relationships among different activities, causes of work (cost drivers) for the entire process and for individual activities, the input requirements to perform each activity, the output generated by each activity, and the cost of each activity.

A fundamental principle governing $\mathrm{ABCM}$ is that costs are controlled by managing activities (Principle \#5). ${ }^{(19)}$ By using ABM a manager can translate a hierarchical organizational chart into a business process as a way to give visibility to individual activities and their costs. A manager can then focus his or her attention on streamlining and optimizing high-cost activities. By applying $\mathrm{ABM}$, managers use a structured methodology to generate cost data and operational information to answer such questions as

- How is the ES\&H business process defined and mapped?

- Why does an activity and its associated costs occur?

- Why do process costs occur?

- Where do the best opportunities exist to reduce the cost of an activity, product, or service?

- How can the business process be changed to improve ES\&H measures of performance?

The process and cost assignment views contain quantitative data about the cost of each activity in the process and contain information about cost drivers, which quantify the causes of cost. The existence of quantitative causal relationships between different causes of cost-resource cost drivers and individual activities, process cost drivers and process activities, and activity cost drivers and the products produced and services delivered-identifies information critical for fact-based decision making. The quantitative and qualitative data generated by the ABCM model and business process mapping focus management attention on high-cost activities, products, and services; the drivers of cost; and support judgments about why work is being performed. ${ }^{(19)}$

\section{Application of $A B C M$ in Occupational and Environmental Health Organizations}

ABCM has been applied and investigated in three case studies of occupational and environmental health organizations. In an occupational medicine department ABCM was used to determine the cost of medical evaluations. For each evaluation there were specific tests to be performed including laboratory tests for blood and urine, chest X-rays, pulmonary function, vision, hearing, and material-specific tests such as blood lead for workers with possible lead exposure. A physician then evaluated the test results and examined the worker as part of each medical evaluation. By combining the different medical examinations with the specific tests required, it was determined that more than 300 different combinations of medical evaluations were provided by this department. Some of the evaluations were driven by OSHA regulations such as those to protect workers exposed to asbestos, beryllium, benzene, and hazardous waste. Other evaluations were part of the practice of any credible occupational medicine department including new hire and termination, periodic, and fitness for duty examinations and tests.

By using ABCM the occupational medicine department was 


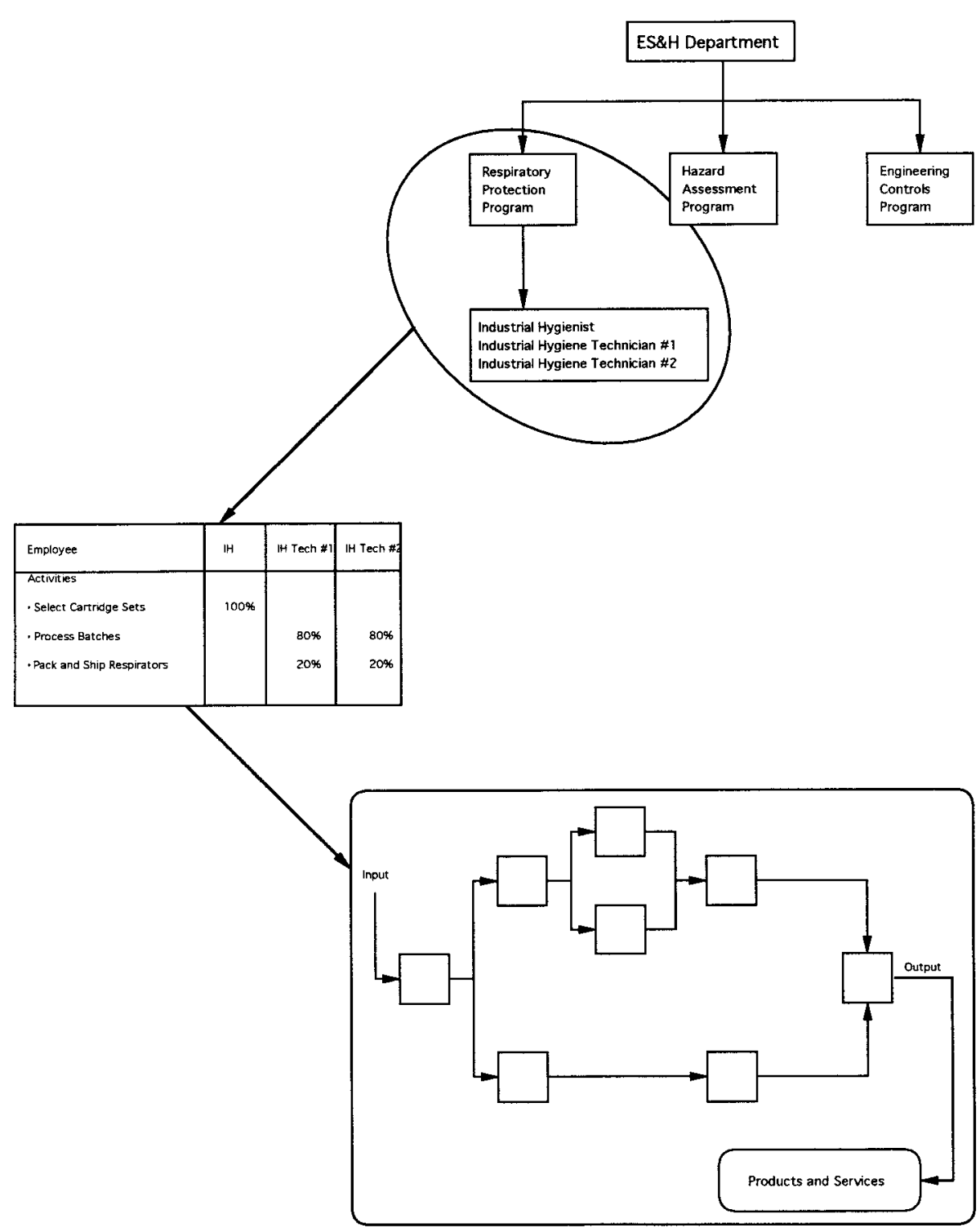

FIGURE 3. Organizational chart of a functional department redefined as activities and reassembled as a business process

able to decompose the costs associated with providing physical evaluations. The ABCM analysis allowed the department to

- identify each natural work group and its associated resources;

- identify resource cost drivers;

- identify the mix of physical evaluations provided;

- understand the cost drivers of the evaluations;

- identify activity cost drivers by using the departmental database;

- identify customers who required specific evaluations;

- determine the cost of specific evaluations and the cost of providing those evaluations to specific customers;

- use the cost data for predictive planning by comparing budgeted costs of providing various medical services with the actual cost incurred; and

- measure the performance of different medical service delivery processes using cost as an outcome measure.

The use of ABCM was also investigated in a fire protection engineering department. In this case it was shown that the process of applying $\mathrm{ABCM}$ was of value to the manager and supervisors involved. They decomposed their organization into its component parts as represented by activities. They logically linked the activities together and identified their products and services. The business process mapping and analysis was significant to these fire protection professionals because it represented a new, disciplined, and logical way of describing the work of fire protection. In addition, when costs were attached to each activity and those costs were traced to the products and services they identified, it caused each of the participants to evaluate critically why he or she was committing budget resources in the way that had been identified. Most significantly, the study participants began to question the decisions they had made about the allocation of increasingly scarce resources. Finally, the ABCM analysis identified the gaps that existed in their departmental database such as tracking the number of fire protection inspections performed and the type and number of repairs performed on fire alarm systems. These data can be used as 
activity cost drivers to quantitatively link cost objects (such as inspections) to specific activities (such as performing fire protection inspections).

ABCM was applied in a third case study of a respiratory protection program. This program was well-established and had been functioning for more than 40 years. As a result, abundant data were available about the types and number of products and services delivered, resource costs, activity cost drivers, and customers. The business process was mapped and costs were determined for each specific activity in the business process. Unit costs were determined for each activity using count data. The total and unit cost of providing the training and face fit-testing services and issuing specific types of respiratory protection was determined.

Many costs could not be attached directly to specific activities. Departmental budget records did not track costs by activities. As a result, many costs were collected in an overhead cost category, which accounted for approximately $30 \%$ of the program's budget. The manager of the respiratory protection program can now track and trace these identified expenses to the activities that use them and the products and services that cause them. With better record keeping and cost tracking, it is expected that a large portion of the $30 \%$ of unspecified overhead expenses can be traced to activities. With the cost data and business process information generated by ABCM the manager can begin to change the way in which the activities are performed as a way to control the costs of the program. Finally, the cost of serving specific groups of customers was quantified.

Ultimately, an ES\&H professional must make decisions about managing his or her department or program. Decisions must be made at each step in the ES\&H quality improvement cycle (anticipation, recognition, evaluation, and control) consistent with an organization's strategic goals, values, and culture. The results of these case studies can be used by the ES\&H professionals in the subject departments. They can use the data and business process information to communicate with senior executives who may make decisions that could affect the way in which health and safety products and services are delivered in the workplace. For example, ES\&H professionals can develop several risk control options for any identified ES\&H problem. By using ABCM they can include business process intelligence and cost data for each control option. Part of the cost input can show how the cost of taking a specific action can be the best choice, even if the technical solution appears to be a high cost in present dollars. The ES\&H professional can present that this high cost can be balanced or offset against any realistic potential future liability that may occur if the control action is not implemented. Such cost/benefit analyses are essential for informed decision making.

\section{CONCLUSIONS}

A BCM is an important business and cost management development because overhead and indirect costs are traced directly to the products that use the activities and thereby generate costs to an organization. The data and information generated by ABCM is useful in quantifying the cost of products, services, customers, and other cost objects; locating the causes of costs; and explaining what drives cost. ABCM is being used to evaluate the impact and implications of all business costs by tracing how activities consume resources and how products consume activities, rather than equally allocating costs to operating departments or products. By understanding which activities cause costs, managers can make better decisions, control costs by managing activities, and perhaps even redirect savings to other ES\&H activities.

Some of the benefits experienced by organizations that have implemented $\mathrm{ABC}$ include a better understanding by managers of the relationship between costs and activities; improved cost control; reduced work activity costs; increased efficiency of work activities performed; more accurate and timely performance feedback to managers; elimination of inaccurate allocation of many overhead and indirect costs to products; more accurate product pricing; and improved decision making. Finally, by using ABCM to develop cost and business process reasons for continuing, maintaining, or expanding the funding of a given ES\&H department or program, worker health and safety, and environmental protection programs, will be better able to compete for a shrinking pool of funding for overhead functions.

\section{ACKNOWLEDGMENTS}

$T$ he authors wish to thank Gary Cokins, ABC Technology, Inc., for his assistance with ABCM concepts and software tools. His contribution has greatly enhanced this article.

\section{REFERENCES}

1. Drucker, P.F.: Post-Capitalist Society. New York: Harper Collins Publishers, 1993. pp. 1-16, 32-47.

2. Hammer, M., and J. Champy: Reengineering the Corporation. New York: Harper Business, 1993. pp. 7-30.

3. Johnson, H.T., and R.S. Kaplan: Relevance Lost: The Rise and Fall of Management Accounting. Boston: Harvard Business School Press. 1991. pp. 12-18.

4. Johnson, D.: 1996 environmental health and safety outlook. The Synergist 7(1):22-23, 28 (1996).

5. Felder, J.: "Monsanto Business Services." Paper presented at the Corporate Environmental, Health, and Safety Excellence: Meeting Business at the Crossroads. New York, February 13-14, 1996.

6. Clayton, G.D.: Industrial hygiene and occupational health in the $21 \mathrm{st}$ century: Summation of papers presented before the Yuma PacificSouthwest Local Section. Am. Ind. Hyg. Assoc. J. 56:1064-1066 (1995).

7. Environmental Business International Inc.: Executive review III. Environ. Bus. J. 9(1):1-11 (1996).

8. Environmental Business International Inc.: Business management. Environ. Bus. J. 8(4/5):1-11 (1995).

9. Johnson, H.T., and R.S. Kaplan: The rise and fall of management accounting. Manag. Account. 68(7):22-30 (1987).

10. Kaplan, R.S.: Management accounting (1984-1994): Development of new practice and theory. Manag. Account. Res. 5:247-260 (1994).

11. Miller, J.G., and T.E. Vollmann: The hidden factory. Harvard Bus. Rev. 63(5):142-150 (1985).

12. Johnson, H.T.: Activity-based management: past, present, and future. Engin. Econ. 36(3):219-238 (1991).

13. Kaplan, R.S.: New systems for measurement and control. Engin Econ. 36(3):201-218 (1991).

14. Cooper, R., and R.S. Kaplan: How cost accounting distorts product costs. Manag. Account. 69(10):20-27 (1988).

15. Cooper, R.: The rise of activity-based costing — part three: How many cost drivers do you need, and how do you select them? J. Cost Manag. 3(1):34-46 (1988)

16. Rotch, W.: Activity-based costing in service industries. J. Cost Manag. 4(2):4-14 (1990).

17. Antos, J.: Activity-based management for service, not-for-profit, and government organizations. J. Cost Manag. 6(2):13-23 (1992). 
18. Chaffman, B.M., and J. Talbott: Activity-based costing in a service organization. CMA Mag. 64(10):15-18 (1990).

19. Cokins, G.: Activity-Based Management: Making It Work, A Managers Guide to Implementing and Sustaining an Effective ABC System. Chicago: Irwin Professional Publishing, 1996. pp. 53-100.

20. Turney, P.B.B.: Common Cents: The ABC Performance Breakthrough. Hillsboro, OR: Cost Technology, 1991. pp. 75-116.

\section{APPENDIX}

\section{Glossary}

Activity: A step in a business process where work that adds value to a product or service is performed using resources.

Activity-based costing: A two-step cost reassignment method that measures the cost of a product or service based on (1) the actual use of budget resources by work activities, and (2) amount of activity resources used to produce a product or service. Yields data about what things cost.

Activity-based management: Concerned with the relationship between individual activities linked together in a business process. Yields data about how and why things cost.

Activity center: A cluster of activities grouped by a common function or process.

Activity cost driver: Measure of the level of effort required and of the frequency with which an activity is performed. Related to activity consumption patterns by products and services.

Activity cost pool: A grouping of the total of all cost elements traced to an activity that exhibit similar cost behavior patterns.

Budget resource cost: When budget resources are traced to activities, they become budget resource costs.

Budget resources: Factors of production used to perform an activity, including labor, equipment, materials, supplies, space, utilities, or any other resource that can be used by an activity. They are considered costs of performing work.

Business process: Sequence of logically related activities that use resources to create products and services of value to a customer.

Cost: Resources committed to achieve a goal.

Cost allocation: Assigning indirect and overhead costs to cost objects.

Cost driver: A factor that affects the cost of an activity, process, or product or service.

Cost element: The budget resource traced to an activity and its cost.
Cost object: The final point to which all costs are traced. Cost objects may be products, services, customers, projects, or any other final destination for costs of interest to a manager.

Cost tracing: In traditional cost accounting, the assignment of direct costs to cost objects. In ABCM, the assignment of resources to activities and activity costs to products or services based on the actual use of resources by activities and the actual use of activities by products and services.

Direct cost: Costs that can be attached to a single cost objective. These costs can be directly linked to or caused by a specific cost object. Examples include raw materials, supplies, and labor.

Factors of production: Budget resources consumed by activities to produce a product or service such as technology, labor, facilities, or energy. They become elements of cost traced to activities.

Indirect cost: Costs that are not easily or economically traced to a specific cost object. Costs that are caused by or can be identified with two or more cost objectives. A local exhaust ventilation system can be considered an indirect cost because more than one product line could conceivably contribute pollutants to the system. These costs are more closely associated with a process than are overhead costs.

Natural work group: A grouping of labor and other budget resources together by common purpose or function. For example, occupational physicians and their associated budget resources comprise a natural work group called "Clinical Staff, MD," while occupational nurses and their associated budget resources comprise a natural work group called "Clinical Staff, RN."

Overhead cost: Costs that cannot be directly linked to producing a product or service, but that provide support. These costs are less closely linked to a process than are indirect costs. Support organizations such as ES\&H departments, legal, and human resources are classic overhead costs.

Products: An outcome of a work activity or business process that is tangible, such as issuing a respirator.

Resource cost driver: Traces and measures the consumption of resources by activities. Assigns budget resource costs to activities based on the use of the resource by the activity.

Services: An outcome of a work activity or business process that delivers intangible assistance in support of a goal, such as training employees to wear respirators.

Transaction: An exchange of information or data between individuals in a business process that generates cost. The work involved in planning, managing, budgeting, administering, measuring, and controlling the work performed in an organization. 